\title{
Discurso-cognição-sociedade: estado atual e perspectivas da abordagem sociocognitiva do discurso'
}

\section{Discourse-cognition-society: current state and prospects of the socio-cognitive approach to discourse}

Tradução de Pedro Theobald (perth@pucrs.br) com revisão do autor. O texto original Discourse-Cognition-Society: Current state and prospects of the socí-cognitive am Christopher Hert \& Piotr Cup (Eds). Contemporary Studies in Critical Discourse Analysis.

Pressor na Universitat Pompeu Fabra UPF), Barcelona, Espanha. Possui doutorado pela Universidade de Amsterdam (1972), com a tese Some aspects of text grammars.

E-mail: vandijk@discourses.org
RESUMO: Este artigo apresenta o estado da arte da abordagem sociocognitiva nos Estudos do Discurso. A teoria relaciona estruturas do discurso com interação social e estrutura social por meio de uma interface sociocognitiva, baseada no argumento de que estruturas discursivas e estruturas sociais diferem quanto à natureza e não podem ser diretamente relacionadas. A teoria cognitiva consiste, por um lado, de uma dimensão pessoal de modelos mentais pessoais (i) dos eventos sobre os quais se fala ou se escreve, e (ii) da própria situação comunicativa (modelos contextuais), e por outro de uma dimensão social que consiste de crenças, conhecimento, atitudes e ideologias socialmente compartilhadas - que controlam os modelos mentais pessoais, e indiretamente todo discurso. Dessa forma, somos capazes de descrever explicitamente como os discursos estão envolvidos na reprodução de problemas sociais como o racismo e o sexismo. Além disso, a análise cognitiva também descreve e explica vários aspectos do próprio discurso, tais como todas as estruturas discursivas baseadas no conhecimento (coerência semântica local e global, evidências etc.) e na ideologia (a polarização de diferentes estruturas discursivas relacionadas a Nós [endogrupo] e Eles [exogrupo]).

Palavras-Chave: Análise crítica do discurso; Abordagem sociocognitiva; Modelos mentais; Modelos contextuais; Conhecimento; Atitudes; Ideologia.

ABSTRACT: This article presents the current state of the art of the socio-cognitive approach in Discourse Studies. The theory relates structures of discourse with social interaction and social structure through a socio-cognitive interface, with the argument that discourse structures and social structures are of a different nature and cannot be related directly. The cognitive theory consists on the one hand, of a personal dimension of personal mental models (i) of the events talked or written about, and (ii) of the communicative situation itself (context models), and on the other hand of a social dimension consisting of socially shared beliefs, knowledge, attitudes and ideologies - which control the personal mental models, and indirectly all discourse. In this way, we are able to explicitly describe how discourses are involved in the reproduction of social problems such as racism or sexism. Moreover, cognitive analysis also describes and explains many aspects of discourse itself, such as all discourse structures based on knowledge (such as local and global semantic coherence, evidentials, etc.), and ideology (such as the polarization of various discourse structures related to Us (ingroup) and Them (outgroup).

KEYwORDS: Critical discourse analysis; Socio-cognitive approach; Mental models; Context models; Knowledge; Attitudes; Ideology. 


\section{Introdução}

estudo crítico do discurso deve basear-se em uma teoria multidisciplinar que, de modo explícito, relacione estruturas discursivas com estruturas sociais para, assim, descrever e explicar como estruturas de poder e abuso de poder são discursivamente apresentadas e reproduzidas. A principal tese de uma contribuição sociocognitiva a essa teoria consiste no fato de que as relações entre discurso e sociedade são cognitivamente mediadas. Neste artigo esboçamos o estado atual dessa abordagem sociocognitiva (ASC) ${ }^{1}$, bem como suas perspectivas futuras, com base em nossa pesquisa dos últimos 30 anos (ver tb. VAN DIJK, 2008).

A maior parte das teorias anteriores e contemporâneas nos Estudos Críticos do Discurso (ECD), bem como nas disciplinas adjacentes, tais como a sociolinguística e a antropologia linguística, supõe uma relação direta entre discurso e sociedade (ou cultura). Nessas disciplinas, geralmente se pressupõe que variáveis sociais tais como classe social, poder, gênero, etnicidade ou idade provocam ou controlam diretamente a variação linguística e as estruturas do discurso. O problema é que a natureza dessas relações causais diretas ou similares não é tornada explícita, mas pressuposta ou reduzida a correlações não explicadas.

Outro problema fundamental é que estruturas sociais e estruturas discursivas pertencem a tipos diferentes e, consequentemente, já não podem entrar em relação causal. Uma teoria sociocognitiva supõe que as estruturas sociais precisam ser interpretadas e representadas cognitivamente e que tais representações mentais afetam os processos envolvidos na produção e interpretação do discurso. 0 mesmo princípio vale para a relação inversa, a saber, como o discurso é capaz de afetar a estrutura social - especificamente

$\overline{1}$ No original, socio-cognitive approach (SCA). N. do T por meio das representações mentais dos usuários da língua como atores sociais.

Limitações teóricas similares caracterizam as abordagens contemporâneas "interacionistas" do discurso, por exemplo, na Análise da Conversação (AC) e na Psicologia Discursiva (PD). Tais abordagens ligam as estruturas do discurso diretamente com estruturas de interação na ordem microscópica da sociedade. Desse modo, elas ignoram que também essa relação é mediada pela cognição: constitui uma verdade trivial que os usuários da língua não só agem, mas também pensam quando falam.

Negar ou ignorar a existência ou relevância dessa dimensão cognitiva de interação constitui, em muitos aspectos, uma versão contemporânea de argumentos similares defendidos há várias décadas pelo behaviorismo, tais como a alegada falta de "observabilidade" ou "sociabilidade" das representações cognitivas. Vários aspectos da conversação, tais como o papel dos significados implícitos ou implicados, permanecem, por isso, sem uma descrição ou explicação clara. De fato, de um modo ainda mais geral, a própria definição da noção fundamental de "ação" sem uma base cognitiva fica, assim, reduzida a um conceito behaviorista de conduta "observável". O mesmo vale para o significado de discurso, de difícil explicação teórica, sob o aspecto da observabilidade, no sentido empirista corrente.

Do ponto de vista da ciência cognitiva contemporânea, tais constatações podem parecer triviais, embora as implicações teóricas e analíticas detalhadas desses pressupostos sejam entendidas só em parte. Mesmo a psicologia cognitiva do discurso até hoje não conta com uma teoria explícita de como os "ambientes" sociais e comunicativos afetam o discurso. Por esse motivo, uma das tarefas deste artigo é esboçar as principais doutrinas de uma tal teoria como o núcleo da interface cognitiva das relações entre discurso e sociedade. 


\section{Cognição}

A interface cognitiva das relações entre discurso e sociedade é tão complexa quanto às próprias estruturas do discurso, por um lado, e às estruturas da sociedade, por outro, que aqui só podemos resumir algumas de suas noções mais relevantes. Em virtude de tal fato, ignoramos muitos detalhes das propriedades da Memória de Trabalho e vários aspectos das Memórias Episódica e de Longo Prazo, do processamento cognitivo, bem como de seus fundamentos neuropsicológicos (dentre os vários estudos contemporâneos nessas áreas, ver, p. ex., BADDELEY, 2007; TULVING, CRAIK, 2000).

Por isso mesmo, focalizaremos aqueles aspectos da estrutura e do papel da cognição pessoal e social que importam diretamente para as propriedades mais fundamentais da produção e compreensão do discurso (para detalhes, ver GRAESSER, GERNSBACHER, GOLDMAN, 2003)².

\subsection{Cognição pessoal vs. Cognição social}

Uma primeira distinção crucial da estrutura cognitiva subjacente ao uso da linguagem e do discurso é aquela que existe entre cognição pessoal e social. A distinção está vagamente refletida na divisão de trabalho entre psicologia cognitiva e social, embora obviamente estejamos tratando de cognição em ambos os casos.

A cognição pessoal explica as maneiras como os usuários individuais da linguagem, como membros de comunidades linguísticas, epistêmicas e sociais, subjetivamente produzem e compreendem o discurso. Embora essa

\footnotetext{
2 Existe uma vasta literatura, não somente em psicologia cognitiva do discurso, mas também sobre as dimensões sociais e discursivas deste artigo. Eis por que citaremos apenas alguns livros relevantes para a leitura de embasamento deste texto, ou onde noções específicas foram emprestadas de outros autores.
}

explicação esteja construída em função de estruturas e processos mentais e neurológicos de usuários individuais da linguagem, ela precisa estar baseada em representações socialmente compartilhadas de atores sociais individuais como membros de diversas coletividades sociais. Ao mesmo tempo tais representações e processos são ativados, aplicados e adaptados às propriedades da interação social e comunicação situada e em curso, por meio das quais são adquiridas, mudadas e socialmente reproduzidas. Em outras palavras, o pessoal e o social no processamento do discurso encontram-se inextricavelmente interligados.

Neste artigo limitamos nossa exposição sobre a cognição pessoal, e consequentemente sobre as propriedades subjetivas e únicas do discurso individual, a um breve resumo do papel de diferentes tipos de modelo mental. A dimensão social da interface cognitiva entre discurso e sociedade será descrita em função de estruturas e papel do conhecimento, por um lado, e atitudes sociais compartilhadas e ideologias, por outro.

\subsection{Modelos de situação}

Nas últimas três décadas, diversos estudos de psicologia cognitiva do discurso mostraram o papel fundamental dos modelos mentais para a produção e compreensão do discurso e, de um modo mais amplo, para a interação e a percepção do ambiente (GARNHAM, 1987; GENTNER, STEVENS, 1983; JOHNSON-LAIRD, 1983; OAKHILL, GARNHAM, 1987; VAN DIJK, KINTSCH, 1983).

Por isso, de modo geral, tem-se tomado como um fato que a compreensão do discurso inclui a ativação, atualização ou construção contínua de modelos de situação que representam os eventos ou a situação de que o discurso trata (VAN DIJK, KINTSCH, 1983). Uma vez que tais modelos são o correlato cognitivo do que tradicionalmente era chamado de aspecto "referencial" do emprego da linguagem, tais modelos também podem ser chamados de 
semânticos. Eles correspondem ao que em termos filosóficos é chamado de tematicidade (aboutness), isto é, o aspecto "intencional" ou representacional do uso da linguagem.

Modelos de situação não devem ser confundidos com o sentido (intensional) do discurso, que constitui um nível e aspecto diferente e específico de processamento do discurso. De fato, modelos de situação não dependem do uso da linguagem: nossa simples experiência e observação $d e$, e nossa participação em eventos ou situações acontecem em função de modelos de situação, quer falemos deles ou não. Em outras palavras, nossa experiência e compreensão correntes dos eventos e situações de nosso ambiente acontecem em função de modelos mentais que segmentam, interpretam e definem a realidade enquanto a "vivemos" (SHIPLEY, ZACKS, 2008). Embora as estruturas de uso da linguagem (p. ex., sentenças e histórias) sejam influenciadas pelas estruturas mais primitivas desses modelos mentais, os modelos mentais de nossas experiências cotidianas são independentes do discurso. Na realidade, a fim de sobreviver, os primatas necessitavam de tais modelos para interagir com seu ambiente antes que soubessem falar (PLOTKIN, 2007).

Acredita-se que os modelos mentais são representados na Memória Episódica, isto é, na parte da Memória de Longo Prazo em que representamos nossas experiências autobiográficas ou "memórias" pessoais (BADDELEY, CONVEY, AGGLETON, 2002; TULVING, 1983, 2002). Embora até o momento nenhuma teoria explícita das estruturas dos modelos mentais tenha sido formulada, é plausível imaginar que esses modelos possam consistir de estruturas hierárquicas formadas por um número limitado de categorias fundamentais que definem a estrutura básica de nossa experiência: um cenário espaço-temporal, participantes com diferentes identidades, papéis e relações, objetivos, e uma ação ou acontecimento. É interessante observar que tais estruturas também aparecem no caso da estrutura semântica das sentenças das línguas naturais (FILLMORE, 1968), bem como em histórias sobre tais eventos e situações (DE FINA, GEORGAKOPOULOU, 2012). Encontramos aqui as primeiras evidências para a projeção de estruturas mentais em estruturas de uso da linguagem e do discurso.

Os modelos mentais são multimodais. Eles representam a experiência complexa, corporificada, de eventos e situações, incluindo aspectos visuais, auditivos, sensório-motores e emocionais de uma experiência (BARSALOU, 2008; ZWAAN, 2004). Nesse sentido, eles são também exclusivamente pessoais. De fato, eles não apenas representam nosso conhecimento de um evento, mas também podem apresentar nossa opinião pessoal sobre o valor ou nossas emoções sobre o evento - que por sua vez podem ser expressos (ou não) de várias maneiras nas sentenças ou histórias sobre tal experiência.

Em suma, a compreensão do discurso não inclui apenas a construção de seu sentido (ou intensão) sob o aspecto de alguma representação semântica, mas também a construção de seus referentes (ou extensão) sob o aspecto de modelos mentais armazenados na Memória Episódica. Em contrapartida, falar ou escrever sobre eventos específicos, como no caso da contação de histórias ou reportagens de notícias, baseia-se nos modelos de situação pessoais, subjetivos, que os usuários da língua constroem a partir de tais situações. Obviamente, tais modelos de situação também podem ser (parcialmente) expressos e comunicados por meio de outros sistemas semióticos, tais como desenhos, pinturas, dança, gestos ou música.

Uma vez que tratamos de modelos mentais como a interface entre o discurso e o ambiente social ou natural, veremos a seguir como as estruturas discursivas se assemelham, mas também diferem das estruturas dos modelos mentais. Uma diferença crucial é que os modelos são muito mais completos, e só parcialmente expressos no discurso, por causa do conhecido fato epistêmico e pragmático de que os receptores precisam apenas de "meia palavra" para reconstruir um modelo mental pretendido 
com a ajuda das inferências baseadas no conhecimento genérico situacional e socioculturalmente compartilhado ao qual voltaremos na sequência. Isso também explica a consequência óbvia de que os modelos de receptor podem ser diferentes dos modelos de falante pretendidos. Os receptores analisam sua compreensão do discurso, isto é, o seu modelo mental, não só com o sentido expresso no discurso, mas também como conhecimento e ideologias socialmente compartilhados. Eles também ativam modelos antigos estritamente pessoais, baseados em discursos e experiências anteriores. Em outras palavras, essa abordagem cognitiva do discurso em função de modelos mentais também explica a distinção clássica entre sentido do falante, sentido do discurso e sentido do receptor.

\subsection{Modelos de contexto}

É estranho que na psicologia cognitiva do processamento do discurso se tenha ignorado até o momento o fato óbvio de que os usuários da língua não só analisam modelos mentais "semânticos" dos eventos ou situações sobre os quais falam, mas também modelos mentais "pragmáticos" daquela experiência ou situação comunicativa em que se encontram envolvidos no momento. Esses modelos mentais dinamicamente cambiantes e subjetivos da situação comunicativa em andamento explicam o que tradicionalmente se chamava de contexto do uso da língua e do discurso, por exemplo, na sociolinguística. Eles também fornecem a necessária interface cognitiva para abordagens interacionistas contemporâneas que não possuem uma teoria explícita do contexto (para uma teoria multidisciplinar do contexto, ver VAN DIJK, 2008a, 2009; ver também GIVÓN, 2005; para uma abordagem mais interacionista do contexto, ver DURANTI, GOODWIN, 1992).

É nesse ponto que chegamos ao cerne da interface cognitiva entre discurso e sociedade. Os modelos de contexto representam os aspectos do ambiente comunicativo, e por consequência os parâmetros sociais do uso da linguagem, definidos como relevantes para os e pelos participantes (para uma abordagem mais abstrata da relevância, ver SPERBER, WILSON, 1995).

Os modelos mentais das situações comunicativas - como todos os modelos mentais - apresentam pelo menos um cenário espaço-temporal, participantes de distintas identidades, papéis e relações, uma ação em andamento e seus objetivos. Específico dos modelos contextuais, no entanto, é que papéis, ação e objetivos dos participantes sejam comunicativos e não apenas, de um modo mais geral, interacionais.

Esses parâmetros de modelos contextuais fornecem a base de indicadores, tais como expressões dêiticas que se referem a tempo, lugar, participantes e ação da situação comunicativa, bem como as condições adequadas dos atos de fala (SEARLE, 1969). Com efeito, a principal função dos modelos de contexto é controlar as maneiras como os usuários da língua são capazes de adaptar seu discurso e interação em andamento à situação comunicativa atual (constantemente cambiante).

Conforme acontece com os modelos de situação semânticos, também os modelos de contexto pragmáticos são multimodais, apresentando especificamente a própria experiência de falar, escrever, escutar ou ler, bem como opiniões e emoções (felicidade, medo etc.) associadas com a situação comunicativa (ver também ROYCE, BOWCHER, 2007).

Como ocorre com todos os modelos mentais, também os modelos de contexto são representados na Memória Episódica. E exatamente como nos modelos de situação (semânticos), mais tarde podemos lembrar ou contar uma história sobre um evento comunicativo anterior de que participamos, da mesma forma que podemos referir-nos a ou falar sobre as propriedades da situação comunicativa atual, por meio de expressões dêiticas ou outros indicadores (LEVINSON, 1993). Nesse caso, a semântica e a pragmática do discurso se sobrepõem porque os modelos de situação e de contexto se sobrepõem. 
Ao pressupor modelos de situação semânticos e modelos de contexto pragmáticos, definimos o núcleo teórico da interface cognitiva entre discurso e sociedade. Assim, em primeiro lugar, os usuários da língua são capazes de representar mentalmente eventos e situações sociais e falar sobre eles, o que é essencial tanto para a sobrevivência da espécie quanto para a interação na vida cotidiana (VAN DIJK, 2014). Ao mesmo tempo, sua fala é controlada por seus modelos de contexto subjetivos representando eventos e situações comunicativas e, pois, sociais, de tal modo que sua fala, e por consequência sua interação comunicativa, é adaptada ao ambiente comunicativo e social. Em outras palavras, assim definimos a base cognitiva dos aspectos semânticos e pragmáticos fundamentais do uso da língua e do discurso, através de uma interface que liga a natureza, as condições e o controle das estruturas discursivas aos eventos e situações representados do mundo social, por um lado, e mais especificamente com os aspectos sociais da situação comunicativa, por outro.

\subsection{0 recurso do conhecimento}

Um dos parâmetros mais importantes dos modelos de contexto é o conhecimento que os usuários da língua precisam possuir a respeito do conhecimento dos destinatários. Virtualmente todas as estruturas da língua, da acentuação à entonação, articulação focada no tópico da sentença, ordem das palavras, primeiro e segundo plano, evidências, modalidades, coerência local e global do discurso e organização esquemática, contação de histórias e argumentação, atos de fala e interação conversacional, são profunda e continuamente influenciadas por um recurso de conhecimento pragmático (recurso C - K-device) que define o Terreno Comum (CLARK, 1996) dos usuários da língua na interação e na comunicação (para detalhes, ver VAN DIJK, 2008a, 2014).
Dessa forma os falantes não precisam expressar, e portanto podem pressupor, a informação ou conhecimento que eles têm ou acreditam que os destinatários já possuem ou podem facilmente inferir por si mesmos a partir do conhecimento socialmente compartilhado (que abordaremos mais adiante).

De forma similar, várias estruturas do discurso devem ser definidas quanto à relação entre informações dadas, conhecidas, pressupostas ou de fundo, por um lado, e conhecimento novo, renovado, insuspeitado ou em primeiro plano, por outro (LAMBRECHT, 1994). De fato, além das várias outras funções da linguagem e do discurso, a função comunicativa é a base e o centro das outras, isto é, a transmissão e aquisição de novos conhecimentos e a operação de relacioná-lo com o conhecimento antigo. Atos de fala tais como asserções e perguntas são, desse modo, definidas pelo aspecto epistêmico dos modelos de contexto.

Os conhecimentos ou crenças dos falantes sobre os conhecimentos e crenças de seus destinatários constitui um aspecto bem conhecido da clássica edição filosófica, psicológica e neurológica de Other minds (GIVÓN, 2005). Além de sua base neurológica quanto a neurônios reflexos que possibilitam a natureza fundamentalmente interativa da linguagem, o conhecimento mútuo e o Terreno Comum no discurso estão baseados na simulação geral dos conhecimentos e intenções dos outros por analogia com os nossos próprios, bem como (modelos de) experiência compartilhada das mesmas ou de situações comunicativas anteriores e o conhecimento sociocultural compartilhado de membros das mesmas comunidades linguísticas e epistêmicas (dentre muitos estudos sobre outras mentes, conhecimento compartilhado e intenções como base da interação humana, ver, p. ex., GOLDMAN, 2006; TOMASELLO, 2008).

O recurso $\mathrm{C}$ continuamente acessa essas diferentes fontes de conhecimento, garantindo que todos os aspectos do discurso em andamento estejam epistemicamente adequados à situação comunicativa atual. 
Vemos que além das outras estruturas de modelos mentais semânticos e pragmáticos subjacentes à produção e compreensão do discurso, e portanto de toda interação verbal, o conhecimento mútuo e compartilhado, bem como seu domínio e expressão constante, são um aspecto fundamental da interface cognitiva do discurso e do ambiente social. Sem tal componente epistêmico cognitivamente (e socialmente) baseado, vários, se não a maioria dos aspectos do discurso, não podem ser explicados.

\subsection{Cognição social I: conhecimento sociocultural}

Vimos que e como modelos de situação semântica e de contexto pragmático são necessários como parte da interface cognitiva entre as estruturas do discurso e as estruturas do ambiente comunicativo e social nas quais e sobre as quais os usuários da língua interagem e se comunicam. Especificamente, elas definem a natureza subjetiva, pessoal e do momento contextual de todo uso da língua e do discurso.

Contudo, os usuários da língua não são apenas indivíduos, mas também atores sociais, membros de grupos linguísticos, epistêmicos e comunidades sociais e grupos sociais, instituições e organizações. Como membros de comunidades linguísticas, eles compartilham uma língua natural. Como membros de comunidades epistêmicas eles partilham diversos tipos de conhecimento sociocultural sobre eventos públicos, bem como estruturas genéricas do mundo natural e social. Como membros de grupos sociais e comunidades, eles compartilham normas e valores e as atitudes e ideologias neles baseadas.

De fato, o recurso C de modelos contextuais não seria capaz de operar sem tal conhecimento sociocultural compartilhado dos membros das comunidades epistêmicas, permitindo as necessárias inferências sobre a natureza da situação comunicativa atual - tais como as normas e condições dos atos de fala, conversações e diversos gêneros de discurso.
De modo similar, tal conhecimento socialmente compartilhado é crucial na própria construção de modelos de situação sobre eventos e situações específicos, especialmente como instanciações ou "aplicações" de conhecimento mais genérico ou abstrato e suas inferências. Assim, somente somos capazes de entender um modelo de situação mental pessoal e específico de uma história sobre o assalto a um banco se tivermos e aplicarmos um conhecimento mais geral sobre bancos, dinheiro, assaltantes e suas ações.

Apesar da natureza fundamental do conhecimento socialmente compartilhado, até agora mal entendemos os detalhes de sua representação na memória, além da suposição de sua representação na parte "semântica" da Memória de Longo Prazo, bem como suas estruturas conceituais e prototípicas, sua organização em escritos e outros esquemas, bem como domínios epistêmicos (p. ex., plantas, animais, seres humanos, grupos sociais etc.), e sua fundação possivelmente multimodal em diversas regiões do cérebro (dentre um vasto número de estudos sobre a psicologia cognitiva do conhecimento, ver, p. ex., ANDERSON, 1980; BARSALOU, 2008; COLLINS, QUILLIAN, 1972; ROSCH, LLOYD, 1978; SCHANK, ABELSON, 1978).

Sejam quais forem os detalhes das estruturas cognitivas e neurológicas da representação do conhecimento socioculturalmente compartilhado em nossa mente/memória e cérebros, é relevante para a nossa discussão, sobretudo, seu papel na construção de modelos mentais de situações comunicativas e outras situações sociais - e portanto como base socialmente compartilhada de todo discurso individual sobre eventos específicos, bem como de toda interação em geral.

Os mesmos modelos mentais estão envolvidos na geração de inferências derivadas do conhecimento geral - por exemplo, como base da coerência local e global do discurso. Em outras palavras, por um lado os modelos mentais necessitam do conhecimento geral para sua construção e, por 
seu turno, conhecimento geral pode ser produzido pela generalização de modelos situacionais. De fato, a maior parte do conhecimento geral que possuímos a respeito do mundo além de nossas experiências cotidianas, como por exemplo sobre catástrofes naturais, guerras, conflitos sociais, países e pessoas famosas, deriva da generalização e abstração de modelos mentais de exemplos específicos de discurso público, geralmente encontrável na mídia.

Em segundo lugar, tal conhecimento geral pode constituir a base cognitiva de gêneros e estruturas de discurso que expressam tal conhecimento diretamente, como no caso típico dos gêneros expositivo e pedagógico, bem como nos argumentos (frequentemente) implícitos do discurso e interação argumentativa. Da mesma forma que algumas estruturas de modelos mentais estão correlacionadas com a estrutura de sentenças e discurso, pode ser que algumas estruturas de discurso expositivo exibam estruturas de conhecimento genérico subjacentes, como no caso das categorias e relações conceituais, bem como os parâmetros fundamentais da realidade, tais como os de tempo e causalidade de eventos, e o tamanho, peso, forma, aparência, ações ou funções de paisagens, coisas, animais e pessoas.

\subsection{Cognição social II: atitudes e ideologias}

Até aqui, grande parte da interface cognitiva entre discurso e sociedade, com exceção dos modelos contextuais, constitui teoria padrão da psicologia cognitiva do processamento do discurso. No entanto, vimos que certos modelos mentais podem apresentar opiniões pessoais de usuários da língua e essas não estão baseadas apenas no conhecimento sociocultural genérico, mas também em representações avaliativas compartilhadas pelos membros de grupos sociais: atitudes, tais como nossas atitudes a respeito de imigração, aborto, casamento homossexual, o livre mercado ou guerras (EAGLY, CHAIKEN, 1993; PRATKANIS, BRECKLER, GREENWALD, 1989).
Como formas de conhecimento socialmente compartilhado, as atitudes provavelmente também estejam representadas na memória semântica ou "social", na qual armazenamos todas as crenças gerais, genéricas e socialmente compartilhadas que são necessárias como base para formar modelos mentais específicos, locais e pessoais, e suas opiniões. Como no caso do conhecimento genérico, no presente pouco se sabe sobre as estruturas cognitivas das atitudes, além de hipóteses sobre sua organização esquemática (p. ex., como uma abstração de modelos mentais sobre imigração), o papel das normas e valores subjacentes que definem o que é bom ou mau, permitido ou proibido.

Como conhecimento socioculturalmente compartilhado, as atitudes são essencialmente sociais (JASPARS, FRASER, 1984). Elas não devem ser confundidas com opiniões pessoais armazenadas em modelos mentais, fato bastante comum na pesquisa tradicional sobre atitudes. Elas são compartilhadas por membros de grupos sociais, cada grupo com sua própria identidade, ações, normas e valores, relações com outros grupos e recursos (como base de seu poder e de sua reprodução). Assim, enquanto o recurso C dos modelos contextuais é a interface específica entre as estruturas de discurso epistemicamente controladas e o conhecimento socialmente compartilhado das comunidades, as atitudes representam a relação entre grupos sociais e seus membros e as maneiras como os membros como usuários da linguagem expressam opiniões sobre acontecimentos sociais, situações, pessoas ou grupos. De um modo mais amplo, tais atitudes constituem a base de todas as práticas sociais dos membros do grupo, como acontece com os preconceitos sociais como base para formas específicas de discriminação e exclusão em geral, bem como para o discurso racista em particular.

Crucial para nosso quadro teórico é que a relação entre estrutura social, tal como as relações de dominação entre grupos, conforme exercidas, por exemplo, nas práticas sociais discriminatórias, é mediada por representações 
mentais de tais atitudes. Também é dessa maneira que - inversamente - o discurso discriminatório e outras práticas sociais estão envolvidos na reprodução diária de estruturas sociais de dominação e resistência. Obviamente, precisamos desse componente como base teórica para todos os estudos críticos do discurso. Assim, racismo, sexismo e outras formas de desigualdade social não influenciam o discurso de maneira direta, nem, vice-versa, o discurso discriminatório influencia as estruturas sociais de dominação. Isso só é possível por meio da interface cognitiva das atitudes socialmente compartilhadas e dos modelos mentais pessoais (que por sua vez influenciam as ações e o discurso pessoais) baseados nelas.

É também através de tais atitudes socialmente compartilhadas que os membros do grupo são capazes de cooperar no alcance de metas pessoais e sociais, porque elas permitem que os falantes e atores sociais individuais infiram as opiniões e objetivos correntes de outros membros do grupo. Dessa forma, o racismo e, por consequência, o poder do grupo branco não é reproduzido por pessoas individualmente intolerantes, mas pela cooperação diária conjunta ou separada de membros (brancos) do grupo para excluir, marginalizar e problematizar membros de outros grupos étnicos em várias situações cotidianas diferentes.

\subsection{Ideologias}

Muitas atitudes sociais apresentam uma base sociocognitiva mais ampla e geral que permite que diferentes atitudes sejam formadas, adquiridas e aplicadas, especialmente por ideologias subjacentes. Assim, existem várias atitudes sexistas ou racistas diferentes em relação a diferentes problemas sociais, mas em um nível mais abstrato elas podem basear-se em ideologias sexistas ou raciais subjacentes. Tais ideologias constituem o esquema cognitivo básico de um grupo e de seus interesses, definido por tais categorias gerais como as identidades, ações, metas, normas e valores, relações com outros grupos e os recursos (de poder) de um grupo. Em outras palavras, junto com o conhecimento de grupo socialmente compartilhado, elas são o núcleo cognitivo da coletividade social (VAN DIJK, 1998).

As ideologias obviamente não apresentam apenas propriedades sociocognitivas, mas também sociais, por exemplo, sob o aspecto de grupos de interesse, seus líderes e instituições, e especialmente como as ideologias dos grupos são compartilhadas, reproduzidas, ensinadas e adquiridas por seus membros, na escola, por doutrinação e por gêneros específicos de discurso, tais como catecismos, programas de partidos, conferências, hinos, canções de protesto, entre muitos outros gêneros (ver CAP, OKULSKA, 2013).

0 quadro teórico esboçado até aqui mostra que existe uma grande distância entre ideologias subjacentes abstratas, por um lado, e sua expressão no discurso, por outro. Dessa forma, as ideologias são especificadas com mais precisão em atitudes socialmente compartilhadas sobre determinados "problemas" ou preocupações do grupo (tais como ideologias racistas podem ser aplicadas e especificadas na formação de atitudes em relação à imigração ou às quotas de emprego).

Tais atitudes, por sua vez, são instanciadas nas opiniões pessoais dos membros do grupo em seus modelos de situação, e esses modelos de situação tendenciosos podem finalmente ser (em parte) expressos no discurso e outras práticas sociais como controlados por modelos de contexto.

O fato também pode significar que opiniões subjacentes e ideologicamente baseadas de membros do grupo em um contexto específico não são expressas, por exemplo, porque são consideradas inadequadas ou, de alguma forma, contraproducentes (contrárias aos objetivos) na situação comunicativa do momento, conforme representada no modelo de contexto do falante. De um modo mais geral, as diferenças entre estruturas do discurso e estruturas de modelo são cruciais, e portanto não podem ser reduzidas mutuamente uma à outra. Assim, podemos explicar muitos aspectos das estruturas do discurso, 
tais como coerência local e global, implícitos, indexadores, condições dos atos de fala, bem como estruturas ideológicas, em função de modelos de situação e contexto subjacentes, mas não reduzimos tais estruturas a modelos mentais.

Acabamos de revisar os principais componentes da interface cognitiva entre estruturas do discurso e estruturas sociais, relacionando modelos pessoais, subjetivo-semânticos e pragmáticos, bem como suas formas subjacentes de conhecimento sociocultural, atitudes e ideologias, com acontecimentos sociais, situações comunicativas representadas, e membros de comunidades epistêmicas e grupos de interesse, instituições e organizações sociais. Esse quadro complexo também explica de que forma comunidades, grupos sociais e relações de poder são reproduzidos pelo discurso e outras práticas sociais baseadas, por sua vez, em modelos mentais pessoais subjacentes e formas de cognição socialmente compartilhadas.

\section{Sociedade}

As mentes dos usuários da língua são concretamente incorporadas em pessoas reais que, além de indivíduos únicos, são membros de grupos, instituições e organizações sociais, e que interagem e se comunicam com outros membros por meio do discurso. Assim, da mesma forma que precisamos de uma interface cognitiva para descrever e explicar várias propriedades do discurso, também precisamos de uma base social, tanto para a interação cognitiva quanto discursiva. Acima, resumimos a dimensão sociocognitiva dessa base social, de modo especial em função de representações mentais social e culturalmente compartilhadas (conhecimento, atitudes, ideologias, normas, valores) de grupos e comunidades. Abaixo, veremos que parte da ordem social, em nível microscópico, é constituída por interação social em geral, e comunicação interativa e discurso em particular. Fundamentalmente, no entanto, a base da sociedade necessita de uma análise que vá além da interação social discursiva. Explicar a fala institucional, por exemplo, pressupõe uma teoria das instituições e de seus papéis na sociedade. 0 conhecimento social compartilhado pressupõe que comunidades epistêmicas e ideologias sejam compartilhadas por grupos específicos.

\subsection{Poder}

Especificamente relevante para o estudo crítico do discurso (ECD) ${ }^{3}$ é a análise do poder e do abuso de poder. Por isso mesmo, do vasto número de características da estrutura social, que evidentemente vão além do escopo de um único artigo, resumiremos brevemente algumas das propriedades do poder e como elas são relacionadas ao discurso (para detalhes, ver VAN DIJK, 2008).

Embora relações de poder entre indivíduos também sejam criadas discursivamente, expressas e reproduzidas pelo discurso, o ECD está especificamente interessado nas relações de poder social entre grupos, organizações ou instituições. Uma das maneiras de definir tal poder social é sob o aspecto do controle. Um grupo tem poder sobre outro grupo se for capaz de controlar ações (específicas) (dos membros) de outro grupo, assim limitando a liberdade do outro grupo (ver, p. ex., LUKES, 2004; STEWART, 2001).

Sendo o discurso uma forma de ação, o poder pode ser exercido controlando o discurso, isto é,

i. estruturas específicas do contexto, tais como cenário (tempo, lugar), participantes (e suas identidades, papéis e relações), atos sociais e suas intenções, bem como conhecimento,

ii. estruturas específicas do discurso (gênero, tópicos, léxico, metáforas etc.).

${ }^{3}$ No original, critical study of discourse (CDS). N. do T. 
Para serem capazes de exercer tal poder, os grupos necessitam de uma base de poder, que pode ser material ou simbólica. Relevante para os recursos de poder simbólico é o acesso preferencial ao discurso público, como no caso das elites simbólicas, tais como políticos, jornalistas e professores. Dessa forma, cada grupo social não é só caracterizado por suas estruturas, relações com outros grupos, as características de seus membros, mas também pela presença ou ausência de recursos de poder. Mais especificamente, um grupo pode ser definido em função da natureza de seu acesso ao discurso público e controle do mesmo. Assim, jornalistas têm acesso ativo à construção de notícias, políticos podem ter acesso ativo a debates parlamentares, e professores à produção do discurso acadêmico, ao passo que a maioria dos cidadãos comuns só tem acesso passivo, como destinatários dessas formas de discurso, ou só como participantes na representação do discurso, por exemplo, como atores de notícias ou cidadãos de quem se fala no discurso político ou educacional.

\subsection{Exemplo: a reprodução do racismo}

Enquanto isso mostra uma dimensão do complexo quadro que relaciona o discurso e uma dimensão específica da sociedade, ou seja, poder social definido como controle, obviamente é necessária uma pesquisa empírica detalhada para dizer exatamente qual grupo ou instituição social controla quais estruturas discursivas em quais situações comunicativas. Assim, se quisermos analisar como o racismo é reproduzido na sociedade como forma de abuso do poder, ou dominação, de um grupo (europeu) sobre outros grupos (não europeus), obviamente precisamos de uma análise mais aprofundada de todas as dimensões. Contudo, mesmo em resumo, o triângulo DiscursoCognição-Sociedade encontra uma excelente ilustração em uma análise do racismo (para detalhes, ver VAN DIJK, 1984, 1987, 1991, 1993, 1998, 2009b).
O racismo como sistema de dominação social tem duas dimensões principais - a das representações socialmente compartilhadas (atitudes preconceituosas), por um lado, e práticas sociais específicas de tratamento ilegal (discriminação). Fundamental para a reprodução do sistema é a reprodução das representações sociais nas quais ele se baseia. Isso acontece através de formas de discurso racista, uma das formas de prática social discriminadora. Embora todos os membros do grupo dominante possam ter acesso a práticas discriminatórias e discurso específicos na interação cotidiana, os mais influentes são os discursos discriminatórios públicos das elites simbólicas na política, na mídia, educação e Universidade. Se essas elites controlam os tópicos, léxico, argumentos, imagens, metáforas do discurso sobre imigrantes e minorias, e se as estruturas do discurso podem afetar, conforme explicado, a formação de modelos mentais de eventos étnicos pelos destinatários, esses modelos também podem ser ideologicamente tendenciosos e, quando generalizados, formam ou confirmam os preconceitos compartilhados no grupo dominante. Finalmente, atitudes negativas específicas podem ser ainda mais abstraídas e formar ideologias racistas subjacentes que sustentam a base sociocognitiva do sistema de racismo. Ideologias racistas, como acontece com várias ideologias, são de modo geral organizadas por um esquema bipolar de Representação Positiva de Si Mesmo e Representação Negativa do Outro (Diminuição), um esquema que também influencia a estrutura de atitudes racistas específicas (p. ex., em relação à imigração ou às quotas), e essas podem por fim influenciar os modelos mentais concretos que os membros do grupo formam de eventos étnicos específicos de que eles participam ou sobre os quais leem ou ouvem falar. Modelos mentais racistas polarizados com base ideológica, dependendo do contexto, podem ser expressos em práticas racistas tais como um discurso organizado de forma similar entre NÓS vs. ELES, em todos os níveis (imagens, tópicos, léxico, metáforas e assim por diante). 
Vemos que a análise de uma forma de dominação social, ou abuso de poder, como o racismo exige a análise das três dimensões fundamentais de Discurso, Cognição e Sociedade. O racismo como sistema baseiase em representações sociais compartilhadas (preconceitos), as quais no entanto só podem ser adquiridas quando estruturas específicas de discurso público influenciam a formação de modelos mentais racistas. Mas, socialmente falando, a produção de tais discursos é controlada pelas elites simbólicas. Uma análise desse tipo não é relevante só no nível global da reprodução social do racismo, mas também para a análise de eventos comunicativos individuais específicos, em nível microscópico.

Certamente não é necessário repetir que este resumo de uma teoria geral, cuja intenção é introduzir e explicar a relevância de uma abordagem sociocognitiva nos Estudos de Crítica do Discurso, não consegue especificar a enorme quantidade de detalhes exigida para a análise de casos específicos. Para uma análise do noticiário racista na imprensa, por exemplo, seria necessária uma análise prévia das representações sociais e preconceitos dos jornalistas, das práticas cotidianas de coleta de notícias, de quem é entrevistado ou tem acesso aos jornalistas, dos processos cognitivos e das limitações do contexto (tamanho, prazo, estilo, conteúdos preferidos etc.) de escrever a notícia, das diversas estruturas das reportagens e das maneiras como estas são lidas, armazenadas e lembradas pelos leitores, entre várias estruturas diferentes e mais detalhadas. Mas também no estudo de casos específicos sempre encontramos uma combinação de estruturas sociais e interação, estruturas do discurso e estruturas cognitivas subjacentes, tais como modelos, conhecimento e ideologias.

\section{Discurso}

\subsection{Ligando discurso com cognição e sociedade}

Apesar do papel fundamental da análise de estruturas cognitivas e sociais para a explicação multidisciplinar do discurso, o componente discurso é naturalmente o objetivo específico e central de qualquer estudo crítico do discurso. Assim, nesta última seção focalizamos as relações entre estruturas discursivas e seu contexto sociocognitivo. Uma explicação mais ou menos completa dessas relações exigiria uma enciclopédia em vários volumes, motivo pelo qual podemos apenas resumir alguns princípios fundamentais. De fato, especialmente também para nossos estudantes, é importante apresentar algumas orientações sobre como fazer uma análise sociocognitiva do discurso (para outras abordagens, ver, p. ex., SCHIFFRIN, TANNEN, HAMILTON, 2013; TITSCHER, MEYER, WODAK, 2000; VAN DIJK, 2007, 2001).

O primeiro princípio de uma análise sociocognitiva (doravante ACG) ${ }^{4}$ é que ela vai além das clássicas teorias e métodos "autônomos" de análise do discurso e da conversação que estudam as estruturas gramaticais, semânticas, pragmáticas, retóricas, estilísticas, narrativas, argumentativas, interativas ou outras estruturas do discurso. Por um lado, uma ACG pressupõe os resultados dessas teorias e métodos mais antigos, mas por outro os corrige e estende, pois várias estruturas (tais como aquelas de coerência ou manipulação, entre outras) só podem ser formuladas em termos sociais e/ou cognitivos.

Em segundo lugar, conforme argumentamos acima e ao contrário do que pressupõem quase todas as teorias em ECD, sociolinguística ou antropologia linguística, não existem ligações diretas entre estruturas sociais e estruturas discursivas, pois toda produção, compreensão e usos do discurso são

${ }^{4}$ No original, sociocognitive analysis (CGA). N. do T. 
mediados pelas representações mentais dos participantes. Por isso, se nos estudos críticos é estabelecida uma ligação entre discurso e poder social, tal explicação deve ser vista como um atalho, como incompleta ou como tacitamente pressupondo estruturas mentais dos membros e processos que permanecem inexplicados na análise.

As estruturas do discurso diferem essencialmente de estruturas sociais, tais como aquelas dos grupos, comunidades, instituições, estados nacionais e suas propriedades e relações. Por isso, repetimos que os últimos só podem influenciar ou ser influenciados pelo discurso por uma interface mental que liga a representação mental de estruturas sociais com as estruturas mentais que representam o discurso. Isso não se aplica somente a macroestruturas e relações sociais, tais como aquelas do sistema de racismo e sua reprodução pelos meios de comunicação de massa, mas também no micronível da interação cotidiana, tais como jornalistas entrevistando atores de notícias. Assim, é verdade que ocorrências de fala constituem ao mesmo tempo atos sociais de fala e formas de (inter)ação social e, como tais, a ordem fundamental da sociedade - isto é, fenômenos em que o discursivo e o social coincidem. No entanto, as estruturas de fala como interação social não devem ser descritas somente nos termos autônomos de, por exemplo, troca de turnos, interrupções e organização sequencial, mas também em função de representações mentais dos participantes. Assim, a Análise da Conversação não explica suficientemente que turnos não ocasionam diretamente próximos turnos, mas a produção mental de próximos turnos é ocasionada pela interpretação, e, pois, a representação mental, de turnos anteriores. Em outras palavras, deveríamos considerar o discurso em três níveis, o nível do sequenciamento do discurso, sequenciamento social ao nível microscópico tanto mediado por sequências de representações mentais quanto processos.

Por exemplo, jornalistas escrevendo uma reportagem ou entrevistando um ator de notícias estão participando de vários atos sociais organiza- cionais, em diversos níveis, mas são capazes de fazê-lo só com base em amplas quantidades de conhecimento social e político em geral, e conhecimento específico de fatos noticiosos representados em modelos mentais. Tal conhecimento ao mesmo tempo multiplica e influencia as estruturas da reportagem ou entrevista, tal como sua coerência local e global, organização esquemática geral, implicações, pressuposições, descrição do ator e da ação, primeiro plano e segundo plano, indicadores, articulação tópico-foco, as estruturas interacionais das entrevistas, e muitas mais.

Em um contexto mais amplo, essas sequências combinadas de discursocognição-ação podem desempenhar um papel na reprodução do racismo ou no gerenciamento de uma crise econômica, e de novo relacionar ações discursivas globais (publicação) de jornais, preconceitos e ideologias de jornalistas, e a reprodução da desigualdade social na sociedade. Em outras palavras, o triângulo Discurso-Cognição-Sociedade pode ser analisado em todos os micro e macroníveis da descrição.

Tome-se por exemplo o uso da metáfora de ondas rotineiramente empregada pelos meios de comunicação de massa e políticos para descrever a chegada de um grande número de imigrantes ao país. Tal metáfora pode ser descrita, primeiramente, como parte de uma sequência de descrição negativa do Outro em uma reportagem ou editorial, e como uma forma de avaliação, a ser considerada na semântica do discurso. Em segundo lugar, uma análise cognitiva descreve a metáfora como um modo de conceptualização encarnada de grandes grupos de estrangeiros como grandes quantidades de água nas quais podemos nos afogar, e portanto como uma ameaça vital. Tal representação faz parte de uma atitude negativa socialmente compartilhada (preconceito) contra os imigrantes, a qual por sua vez pode estar baseada em uma ideologia racista. Em terceiro lugar, a metáfora empregada dessa maneira por políticos e jornais, a fim de estimular o temor da imigração, constitui socialmente um modo de (re)produzir o 
racismo e de politicamente persuadir pessoas a votarem a favor de partidos de candidatos contrários à imigração. Evidentemente cada um desses níveis e dimensões de explicação da metáfora necessita de uma análise bem mais detalhada, mas deveria estar claro que uma análise crítica adequada exige todos os níveis de descrição. Limitar a análise da metáfora a uma mera figura de estilo semântico-retórica ou a um modo de pensar, enfatizando grandes números de pessoas, obviamente seria uma subanálise inadequada dos dados.

\subsection{Uma amostra de análise ACG: um editorial}

Para ilustrar esses princípios gerais, vamos examinar com mais detalhe como as estruturas do discurso devem ser relacionadas com as de cognição e sociedade. Como exemplo, usamos um editorial de jornal, um gênero distinto do discurso diário que, no entanto, recebeu pouca atenção teórica nos estudos de discurso e de gênero. Socialmente, esse gênero constitui um macroato de rotina na expressão da opinião pública e formação (dos editores) de um jornal, funcionando no sentido de influenciar a opinião pública a respeito de eventos e problemas sociais e políticos relevantes. Cognitivamente, os editoriais expressam opiniões, atitudes e ideologias, e pressupõem um vasto conhecimento social e político, e por isso exigem uma análise cognitiva para descrever sua produção, recepção e reprodução em comunidades epistêmicas e grupos ideológicos. Discursivamente, os editoriais constituem um gênero de discurso persuasivo. Podemos, por isso, esperar uma variedade de estruturas retóricas e argumentativas, apreciações, estruturas ideológicas, descrições de eventos sociais, atores e situações, estruturas epistêmicas, e estruturas pragmáticas de asserções, recomendações, conselhos para outros atores sociais e instituições, bem como formas de polidez ao criticar atores ou instituições poderosas. $\mathrm{O}$ importante é que todas essas estruturas discursivas, cognitivas e sociais, estratégias e processos ocorrem em combinação, e em vários níveis, ao mesmo tempo.

O texto que usamos para a análise é um editorial sobre imigração publicado no dia 13 de dezembro de 2012 no tabloide britânico The Sun, conhecido por sua posição contra a imigração.

\section{The Sun afirma}

\section{2 o impacto do influxo}

3 SE você pensa que o país está mudando diante de seus olhos, você está certo. Ele está.

4 A prova está no Censo de 2011. Ele mostra um aumento de três milhões na população

5 da Inglaterra e País de Gales nascida no estrangeiro desde 2001.

6 E na estatística mais alarmante do Censo, os londrinos que se descrevem como

7 britânicos brancos estão em minoria, de apenas 45 por cento.

8 A imigração pode ser sinal de uma sociedade dinâmica. O Sudeste em especial

9 sofreria uma parada sem os dedicados trabalhadores estrangeiros.

10 A imigração controlada de recém-chegados talentosos é bem-vinda, e os Jogos

11 Olímpicos mostraram o lado simpático e positivo da nova face da Grã-Bretanha.

12 Mas a escala do influxo, nesse ritmo, levanta sérias questões.

13 Os Trabalhistas, que irresponsavelmente escancararam nossas portas ao mundo, nunca

14 perguntaram à Grã-Bretanha se ela queria um tal nível de imigração.

15 Nem pensaram como serviços de moradia, hospitais e escolas poderiam dariam conta.

16 Eles não podem. 
17 E a mão-de-obra estrangeira barata e ilimitada está frustrando as tentativas do Governo

18 de fazer o trabalho pagar melhor do que os benefícios.

19 O debate sensato sobre imigração foi calado pela venenosa acusação dos Trabalhistas

20 de "racismo" contra quem quer que se atreva a levantar o problema.

21 O resultado é que os imigrantes sofrem tanto quanto qualquer outro com os serviços

22 públicos sobrecarregados.

23 No mínimo, o Censo de 2011 já está atrasado à medida que novos migrantes chegam.

24 E nem inclui dezenas de milhares que estão aqui ilegalmente.

25 As próximas décadas verão outras mudanças na nossa fisionomia nacional. Mas não é

26 possível fazer o relógio voltar atrás.

27 O desafio agora é garantir que no futuro a imigração esteja de acordo com o que o país

28 pode suportar.

\section{Análise de contexto}

O estudo sistemático do discurso não exige apenas uma análise das estruturas discursivas, mas também das estruturas do contexto, definidas como os parâmetros relevantes da situação comunicativa como é entendida pelos participantes em seus modelos de contexto. Assim, supõe-se que o jornalista que escreve este editorial possui um modelo de contexto definido pelos parâmetros à esquerda, e uma seleção de propriedades do discurso, à direita do Quadro 1.
Quadro 1 - Parâmetros de contexto e manifestações discursivas do editorial

\begin{tabular}{|c|c|}
\hline Parâmetros de contexto & Estruturas de discurso \\
\hline $\begin{array}{l}\text { - a dimensão espaço-temporal do evento } \\
\text { comunicativo } \\
\text { - ele ou ela como jornalista do The Sun e como } \\
\text { cidadão britânico (entre outras identidades), } \\
\text { - no papel de atual autor de editoriais, } \\
\text { escrevendo para leitores do Sun, } \\
\text { - comprometido com o discurso de afirmar } \\
\text { opiniões e produzir um editorial, definido } \\
\text { como um gênero jornalístico, bem como outras } \\
\text { ações sociais, } \\
\text { - com o objetivo de influenciar as opiniões dos } \\
\text { leitores e a política de imigração dos políticos } \\
\text { britânicos, } \\
\text { - e expressando atitudes e opiniões e } \\
\text { pressupondo conhecimento sobre a } \\
\text { imigração recente e a crescente diversidade } \\
\text { étnica do país, entre muitas outras formas de } \\
\text { conhecimento socialmente compartilhado, } \\
\text { bem como ideologias sociais e políticas } \\
\text { subjacentes. }\end{array}$ & $\begin{array}{l}\text { - Data do artigo: } 13 \text { de dezembro de 2012; } \\
\text { - Localização: Londres; expressões dêiticas: } \\
\text { o país (3, 27), agora (27); próximas décadas } \\
\text { (25); presente do indicativo; } \\
\text { - The Sun afirma; expressões dêiticas: nossa } \\
\text { fisionomia nacional (25); nossas portas (13) } \\
\text { - The Sun afirma (1); expressões dêiticas: você } \\
\text { (3) } \\
\text { - Expressões de opinião: estatística ... } \\
\text { alarmante (6); levanta sérias questões (12), os } \\
\text { Trabalhistas, que irresponsavelmente (...) (13), } \\
\text { venenosa acusação dos Trabalhistas (19), } \\
\text { - O desafio agora é ... (27-28) } \\
\text { - Conhecimento: O país está mudando; } \\
\text { estatística; próximas décadas verão..., etc. } \\
\text { - Atitude negativa em relação à imigração e à } \\
\text { política dos Trabalhistas. }\end{array}$ \\
\hline
\end{tabular}

Esses parâmetros de contexto constituem propriedades relevantes da situação comunicativa da escrita editorial porque eles sistematicamente controlam e definem a adequacidade nessa situação. Isto é, um editorial é adequado se, publicado em um jornal, em uma determinada data, e em uma cidade e país específicos, escrito por um editorialista, expressar opiniões sobre eventos ou uma situação recentes, e pretende influenciar a opinião pública e a política social ou de ação. No quadro de uma ASC isso significa que estruturas do discurso não são apenas descritas como tais, mas também controladas pelos parâmetros cognitivos do modelo de contexto, conhecimento, atitudes e ideologias do escritor, bem como suposições sobre os parâmetros cognitivos dos leitores. Essa análise discursivo-cognitiva é então por fim situada na moldura institucional-organizacional do jornal, 
sua relação com os leitores e com outras organizações ou instituições, tais como o governo. Observe-se, no entanto, que tal descrição não constitui simplesmente o resultado da descrição macrossociológica pelo analista, mas está representada no próprio modelo de contexto do escritor e dos leitores. Em outras palavras, a análise do discurso está totalmente integrada com uma análise cognitiva e social.

\section{Estruturas de texto}

Considerando que uma análise completa de todas as estruturas discursivas relevantes do editorial exigiria várias centenas de páginas, focalizamos aquelas estruturas variáveis especificamente controladas por estruturas cognitivas e sociais. Isso significa que ignoramos estruturas gramaticais obrigatórias do inglês que não variam por cognição e contexto, bem como aquelas da gramática específica do discurso, tais como a interpretação dos pronomes e verbos das orações mínimas Ele está (It is [3]) ou Eles não podem (They can't [16]), seguindo a primeira oração das mesmas linhas, e definindo um estilo compacto específico de sintaxe editorial.

\subsection{Estruturas semânticas}

Dado seu papel central na análise do discurso além da sintaxe da oração, e para a análise crítica do discurso em especial, vamos focalizar as estruturas semânticas do editorial.

Macroestrutura semântica. A coerência geral do discurso é definida por sua macroestrutura semântica ou tópico do discurso, dominando os sentidos locais do discurso como parcialmente expressos por suas orações constituintes. Assim, todo o texto está conceptualmente organizado por macroproposições, tais como "A imigração não controlada é ruim para o país". Parte dessa macroproposição está expressa convencionalmente pela manchete como uma categoria obrigatória da estrutura esquemática convencional (sua superestrutura) do editorial: $O$ impacto do influxo. Mas localmente ela organiza toda a informação semântica relacionada à chegada de muitos (alegadamente excessivos) imigrantes: população nascida no estrangeiro (4-5), aumento de três milhões (4), britânicos brancos (6-7), a imigração pode ser sinal de uma sociedade dinâmica (8), novos imigrantes chegam, etc. Outro tópico principal, que controla diversas proposições locais, é, por exemplo, que a política de imigração dos Trabalhistas foi irresponsável, bem como o tópico que define a recomendação textual do editorial, de que a política do governo agora deve limitar a imigração.

Embora se acredite que as macroestruturas semânticas definam a noção de tópico geral do discurso, elas nem sempre são explicitamente expressas no texto. Na verdade, elas definem os níveis mais altos do modelo de situação mental que representa sentidos gerais do autor e leitor do discurso. Em outras palavras, tais estruturas do discurso só podem ser definidas em função de estruturas cognitivas subjacentes, tal como a natureza hierárquica dos modelos mentais. Ao mesmo tempo, essas macroestruturas são também aqueles sentidos gerais mais lembrados pelos leitores.

É nesse ponto que também as funções sociais e políticas do editorial e seus tópicos gerais desempenham um papel. The Sun, como um tabloide influente sobre milhões de leitores, tem uma influência significativa sobre a opinião pública e as políticas do governo. Desse modo, suas opiniões gerais sobre a imigração não têm relevância apenas local para a interpretação deste editorial em especial, mas desempenham um papel fundamental no debate nacional. Os modelos mentais de eventos específicos e as opiniões apresentadas neles também influenciam representações mentais socialmente compartilhadas, isto é, atitudes e preconceitos sobre imigração e imigrantes. Em outras palavras, nossa análise sociocognitiva relacionou estruturas de discurso (tópicos, macroestruturas), com estruturas de nível superior de 
modelos mentais e seu destaque na memória episódica, e essas por sua vez com atitudes socialmente compartilhadas, e a influência sobre a opinião pública de cidadãos e eleitores, políticas de governo e política partidária. A apreciação negativa explicitamente expressa neste editorial se relaciona de um modo mais específico com o poderoso papel dos meios de comunicação de massa, e especialmente de um tabloide como The Sun, e suas relações com os partidos políticos, e consequentemente como parte da estrutura de poder no país.

Em resumo, tópicos de discurso de editoriais são relevantes do ponto de vista sociopolítico, mas essa relevância é cognitivamente mediada pelo papel de tópicos na memória, e, pois, no processamento do discurso, da compreensão, e consequentemente para a formação da opinião pública, e suas consequências para as políticas nacionais, como a principal função persuasiva dos editoriais.

Coerência local. O discurso não é coerente apenas em nível global, mas também local. Essa coerência local assume duas formas, uma intensional (sentido) e uma extensional (referencial). Relações intensionais são funcionais e situam-se entre proposições expressas, tais como Generalização, Especificação, Exemplo, Explicação, e assim por diante.

Dessa forma, na linha (1) a breve oração final It is (Ele está), é uma Repetição e Confirmação do que é afirmado na oração condicional que a antecede. E nas próximas linhas, a prova mencionada na linha (4) é seguida de uma proposição sobre um aumento de três milhões que constitui uma Especificação dessa prova. A fim de poderem estabelecer essas relações, contudo, o autor e o leitor precisam ativar um conhecimento conceptual do mundo, relacionando Censo com dados quantitativos sobre a população.

Por outro lado, a coerência não está baseada apenas em relações de sentido e conhecimento conceptual, mas também definida em função de relações causais, temporais da parte com o todo entre os fatos denotados pelas orações do discurso, tais como elas são representadas nos modelos mentais de autores e leitores. Com efeito, nesse sentido um discurso é coerente se tiver um modelo mental. Assim, o acontecimento do país em mudança mencionado na linha 1 está relacionado à causa de um aumento de três milhões na linha 4 . Tal proposição causal posposta funciona ao mesmo tempo intencionalmente como uma Explicação. Dessa forma, a maioria das proposições deste editorial é localmente conectada por relações temporais e causais diretas ou indiretas nos modelos mentais do autor, tais como:

- Aumento de três milhões na população nascida no exterior $\rightarrow$ País está mudando

- Brancos em Londres são minoria $\rightarrow$ País está mudando

- Sem trabalhadores estrangeiros dedicados $\rightarrow$ Sudeste pararia $\rightarrow$ imigração pode ser sinal de uma sociedade dinâmica

- (Mas) Mão-de-obra estrangeira barata e ilimitada $\rightarrow$ Frustra tentativas do governo de tornar o trabalho economicamente mais compensador que os benefícios etc.

Observe-se, porém, que com frequência as relações temporais e causais que definem modelos mentais se encontram apenas implícitas no discurso, e exigem inferências que mostrem um conhecimento socioculturalmente compartilhado do mundo. Em outras palavras, também a coerência do discurso local é multiplamente dependente das estruturas de modelos mentais subjacentes e de um conhecimento sociocultural mais amplo.

Mas quais são as condições sociais e políticas ou funções desse tipo de coerência local, além do fato óbvio de que o conhecimento sociocultural é definido por comunidades epistêmicas? Em primeiro lugar, tal coerência local também depende de atitudes de grupo e ideologias. Desse modo, para descrever o fato de que em Londres as pessoas brancas constituem agora uma minoria nos termos estimativos negativos de uma "estatística 
alarmante", pressupõe uma atitude e ideologia segundo a qual Londres ou a Grã-Bretanha deveria ser branca, ou que os brancos deveriam pelo menos ser uma maioria. Mais importante, porém, é a afirmação de que o aumento da imigração é mau para o país porque, entre outras coisas, moradia, hospitais e escolas não seriam suficientes. Esse raciocínio causal, no entanto, pressupõe um modelo mental em que expressamente os estrangeiros são um problema, não o fato de que há mais gente no país. De fato, o jornal não faria objeções a um aumento da população autóctone e ignora que um aumento de trabalhadores estrangeiros leva a um aumento de receita para pagar escolas, moradia e hospitais extras e, logo, significaria um aumento de pessoal, com um efeito positivo sobre o mercado de trabalho. Em outros termos, a coerência local deste editorial tem suas premissas em um modelo mental específico da atual situação do Reino Unido, no qual os estrangeiros são mostrados como uma das principais causas da derrocada social. Tal modelo em si é uma concretização de uma atitude negativa socialmente compartilhada em relação à imigração, baseada em uma ideologia racista ou xenófoba.

Por fim, no relato triangular da análise sociocognitiva, esses modelos mentais, atitudes e ideologias expressos no editorial de um tabloide influente apresentam importantes condições sociais e consequências, sobretudo como contribuição à formação ou confirmação de atitudes racistas no seio da população, por um lado, e do ponto de vista político como oposição ao Partido Trabalhista e como partidário do Partido Conservador e sua política antiimigração. De novo, os sentidos do discurso e as representações mentais que lhes subjazem não são inocentes, mas multiplamente conectadas a condições e consequências sociais e políticas. Observe-se, porém, que a relação discursosociedade não é direta, mas mediada por modelos mentais de jornalistas e leitores, e atitudes e ideologias sociais e políticas compartilhadas, sem os quais o discurso não faria sentido na situação comunicativa.
Declarações de isenção e negação do racismo. Uma característica marcante do discurso sobre imigrantes são as declarações de isenção, que expressam uma breve apresentação positiva de si mesmo (p. ex., Não sou racista...) com extensa e dominante apresentação negativa do outro (mas...). Este texto é um exemplo característico de uma tal declaração. Assim, em 2012 até mesmo The Sun não pode mais defender abertamente a posição racista extrema de que a Grã-Bretanha deveria ser ou permanecer branca e sem trabalhadores estrangeiros. Pelo contrário, nas linhas 8-9 faz-se a concessão de que um tipo específico de imigrantes (dedicados e talentosos) pode ser positivo para uma sociedade "dinâmica" e a nova face da Grã-Bretanha. Assim, o principal argumento do editorial não é contra a imigração ou os imigrantes em geral, mas contra "a escala do influxo" - ameaçando que os brancos podem tornar-se uma minoria em seu próprio país ou cidade. Além disso, a afirmação pressupõe que a maioria dos imigrantes não é branca, e dificilmente seria coerente com uma resistência contra imigrantes da Romênia e da Bulgária a que o jornal e outras instituições conservadoras estão se opondo.

Declarações de isenção não só apresentam estruturas semânticas características, mas implicações contextuais e cognitivas especialmente importantes. Sobretudo, elas expressam modelos negativos específicos de eventos de imigração recentes, bem como atitudes negativas mais gerais contra os imigrantes. Contudo, tais opiniões e atitudes podem ser incoerentes com normas e valores liberais, modernos, não racistas ou não xenófobos e, portanto, com a imagem pública do falante ou autor. Daí a relevância contextual da primeira parte par de uma declaração de isenção como forma de apresentação positiva de si mesmo, cuja intenção é bloquear avaliações negativas dos destinatários.

As condições e consequências sociais e políticas das declarações de isenção são evidentes e podem ser formuladas em função de imagem social, 
prestígio, e por conseguinte o capital simbólico dos falantes, autores e instituições. Ao mesmo tempo, como parte de um discurso persuasivo, elas podem diminuir opiniões negativas dos autores, elevando a chance de que seu argumento seja aceito, o que intensifica a influência social e política do jornal - e seu poder. Simultaneamente, ao enfatizar a parte negativa da declaração de isenção, o jornal aumenta o preconceito étnico na sociedade e dessa forma contribui para a reprodução do racismo.

Essa preocupação é muito relevante no modelo de contexto do autor, pois se torna evidente nas linhas 19-20, que repetimos integralmente:

O debate sensato sobre imigração foi calado pela venenosa acusação dos Trabalhistas de "racismo" contra quem quer que se atreva a levantar o problema.

Com efeito, neste editorial, tal como em muitas notícias e artigos de opinião do mesmo jornal e de outros órgãos da mídia conservadora, a negação de racismo, e o ataque aos antirracistas, constituem uma estratégia padronizada de discurso negativo sobre a imigração. No exemplo, isso é feito por meio de vários outros movimentos estratégicos de discurso persuasivo ostentando as típicas estruturas bipolares do discurso ideológico, no qual as qualidades positivas de endogrupos e as qualidades negativas de exogrupos são enfatizadas:

- imprecisão ("levantando a questão" em lugar de lutando contra a imigração),

- consenso não partidário ("qualquer um que...),

- apresentação positiva de si mesmo ("debate sensato", "atreva"),

- apresentação negativa do outro, metáfora e hipérbole ("acusação venenosa", "silenciado" pelos Trabalhistas),

Metáfora. 0 estudo da metáfora conceptual trouxe uma contribuição significativa à análise crítica do discurso porque mostrou como certas expressões metafóricas são relacionadas a maneiras incorporadas de pensar. Daí que a ligação entre discurso e cognição seja parte inerente da própria descrição do discurso metafórico. $O$ fato também se aplica especificamente ao discurso público sobre imigração, como já vimos ao discutirmos o exemplo do emprego onipresente da metáfora da ONDA para a chegada de grandes grupos de imigrantes. Argumentamos que essa metáfora certamente não é inocente, pois ela precisamente definia modelos de situação em destinatários que enxergam a imigração como ameaça, como perigo de uma inundação de imigrantes, e consequentemente de propagar o medo entre a população. Não surpreende que também neste editorial metáforas similares tenham destaque, como no título que expressa o tópico: influxo (repetido na linha 12), bem como na ação, neste contexto negativo, de abrir as portas atribuído aos Trabalhistas. De maneira similar, acusações de racismo são conceptualizadas como venenosas (19), e portanto também expressam ideologicamente a representação negativa do Outro, enfatizando a ameaça a um debate "saudável".

A implicação social e política de tais modelos mentais e sua generalização em atitudes e ideologias compartilhadas não precisam ser explicadas como as campanhas eleitorais de vários partidos na Europa mostraram, com metáforas ameaçadoras semelhantes - por exemplo, Das Boot ist voll (O barco está cheio), na Alemanha -, que este editorial deixa explícitas em expressões como "com o que o país pode suportar" (27-28).

Outras estruturas discursivas. Por uma questão de brevidade, acabamos de focalizar apenas algumas estruturas do discurso, na maioria semânticas. O motivo dessa análise sucinta foi mostrar como estruturas específicas do discurso apresentam bases essenciais para sua descrição e explicação. Também vimos que as estruturas combinadas discursocognição são elas mesmas relacionadas a conhecimento, atitudes e ideologias compartilhadas por grupos, comunidades e organizações, e que 
objetivos sociais e políticos, status, influência e poder tanto condicionam quanto decorrem dessas práticas discursivas através da mediação cognitiva.

Em nosso exemplo, pois, precisaríamos dedicar-nos a uma detalhada análise da argumentação do jornal, parcialmente explicitada em nossa análise da coerência local e suas proposições implícitas. O principal ponto de vista é que o Reino Unido não pode lidar com a migração (maciça), e os argumentos são buscados especialmente na suposta "sobrecarga" dos serviços públicos. Para que esses e outros argumentos sejam convincentes, eles também precisam tornar explícitas várias suposições implícitas de modelos mentais e derivadas de conhecimento e atitudes sociais compartilhados. Social e politicamente o mesmo argumento é relevante porque ele aborda especialmente as preocupações dos cidadãos sobre a qualidade dos serviços públicos, confirmando, assim, o preconceito de que os estrangeiros são a principal causa de sua má qualidade.

Parte da argumentação, e típica do discurso e das reportagens negativas sobre a imigração, é o jogo de números (três milhões, 45\%, etc.) do editorial, sustentando a dimensão quantitativa crítica do argumento principal: imigrantes demais (ou, em um estilo mais formal: a escala do influxo, 12). Outra vez, essas não são apenas hipérboles retóricas ou de sentido, mas confirmam a natureza encarnada, ameaçadora, do modelo mental apresentado por The Sun

Entre muitas outras estruturas semânticas e retóricas, argumentos semelhantes podem ser desenvolvidos para o estilo Sun de aliterações (Impacto do Influxo), estilo coloquial na abordagem dos leitores (se você pensa...), hipérboles e descrição dos piores casos (estatística alarmante, mão-de-obra barata ilimitada), várias formas de autoapresentação positiva (sociedade dinâmica, recém-chegados são bem-vindos, lado simpático e positivo da nova face da Grã-Bretanha, etc.).

\section{Conclusão}

O estudo do discurso deve ser multidisciplinar. 0 uso da língua e o discurso são ao mesmo tempo atos linguísticos, cognitivos, socioculturais e políticos. Uma teoria coerente do discurso deve explicitar como esses atos estão relacionados, tanto no nível da micro quanto da macroanálise. Especialmente também para os Estudos Críticos do Discurso é fundamental que as estruturas do discurso não sejam diretamente relacionadas com estruturas sociais de grupos, poder e dominação. 0 discurso só pode ter condições e consequências sociais e políticas se reconhecermos que ele é produzido por usuários da língua como participantes sociais que não só falam e agem, mas também pensam, sabem e sentem. Isso significa que do mesmo modo que nossa análise do discurso deve ser sistemática e detalhada, também a análise cognitiva subjacente deve ser explícita e sofisticada. Só com essa ligação ausente tornada explícita, seremos capazes de entender como o discurso é capaz de funcionar na reprodução do abuso de poder e na resistência contra ele. Uma breve análise, especialmente de algumas das estruturas semânticas de um editorial do jornal The Sun, mostra como uma análise sociocognitiva relaciona estruturas do discurso com estruturas sociais, por meio de uma análise de estruturas cognitivas, e como tal editorial pode contribuir para a reprodução do racismo na sociedade.

\section{Referências}

ANDERSON, J. R. Concepts, propositions, and schemata: What are the cognitive units? Nebraska Symposium on Motivation. Lincoln: University of Nebraska Press, 1980.

BADDELEY, A. D. Working memory, thought, and action. Oxford; New York: Oxford University Press, 2007. http://dx.doi.org/10.1093/acprof:oso/9780198528012.001. 0001 
BADDELEY, A.; CONVAY, M.; AGGLETON, J. (Eds.). Episodic memory. New directions in research. Oxford: Oxford University Press, 2002. http://dx.doi.org/10.1093/acprof:o so/9780198508809.001.0001

BARSALOU, L. W. Grounded cognition. Annual Review of Psychology, 59, 617-645, 2008. http://dx.doi.org/10.1146/annurev.psych.59.103006.093639

CAP, P.; OKULSKA, U. (Eds.). Analyzing Genres in Political Communication: Theory and Practice. Amsterdam: Benjamins, 2013.

CLARK, H. H. Using Language. Cambridge, England: Cambridge University Press, 1996. http://dx.doi.org/10.1017/CB09780511620539

COLLINS, A. M.; QUILLIAN, M. R. Experiments on semantic memory and language comprehension. In: GREGG, L. W. (Ed.). Cognition and learning. New York: Wiley, 1972.

DE FINA, A.; GEORGAKOPOULOU, A. Analyzing Narrative. Discourse and Sociolinguistic Perspectives. Cambridge: Cambridge University Press, 2012.

DURANTI, A.; GOODWIN, C., (Eds.). Rethinking Context: Language as an Interactive Phenomenon. Cambridge: Cambridge University Press, 1992.

EAGLY, A. H.; CHAIKEN, S. The psychology of attitudes. Fort Worth: Harcourt Brace Jovanovich, 1993.

FILLMORE, C. J. The case for case. In: E. BACH, E.; HARMS, R. T. (Eds.). Universals in linguistic theory. New York: Holt, Rinehart \& Winston. 1968. p. 1-88.

GARNHAM, A. Mental models as representations of discourse and text. Chichester, West Sussex, England; New York: E. Horwood Halsted Press, 1987.

GENTNER, D.; STEVENS, A. L. (Eds.). Mental models. Hillsdale, N.J.: Erlbaum, 1983.

GIVÓN, T. Context as Other Minds. The pragmatics of Sociality, Cognition and Communication. Amsterdam: Benjamins, 2005.

GOLDMAN, A. I. Simulating minds. The philosophy, psychology, and neuroscience of mindreading. Oxford: Oxford University Press, 2006. http://dx.doi.org/10.1093/01951 38929.001 .0001

GRAESSER, A. C.; GERNSBACHER, M. A.; GOLDMAN, S. R. (Eds.). Handbook of discourse processes. Mahwah, N.J.: L. Erlbaum, 2003.

JASPARS, J.; FRASER, C. Attitudes and social representations. In: FARR, R. M.; MOSCOVICI, S. (Eds.). Social representations. Cambridge/Paris: Cambridge University Press/Maison des Sciences de l'Homme. 1984. p. 101-123.
JOHNSON-LAIRD, P. N. Mental models. Towards a cognitive science of language, inference, and consciousness. Cambridge, Mass.: Harvard University Press, 1983.

LAMBRECHT, K. Information structure and sentence form. Topic, focus, and the mental representations of discourse referents. Cambridge; New York, NY: Cambridge University Press, 1994. http://dx.doi.org/10.1017/cbo9780511620607

LEVINSON, S. C. Deixis. Entry in the Encyclopedia of Language and Linguistics. Oxford: Pergamon Press, 1993.

LUKES, S. Power. A radical view. Houndmills, Basingstoke, Hampshire New York: Palgrave Macmillan, 2004.

OAKHILL, J.; GARNHAM, A. Interpreting elliptical verb phrases at different times of day: Effects of plausibility and antecedent distance. Language and Speech, 30(2), 145-157, 1987.

PLOTKIN, H. C. Necessary knowledge. Oxford; Toronto: Oxford University Press, 2007. http://dx.doi.org/10.1093/acprof:oso/9780198568285.001.0001

PRATKANIS, A. R.; BRECKLER, S. J.; GREENWALD, A. G. (Eds.). Attitude structure and function. Hillsdale, NJ: Erlbaum, 1989.

ROSCH, E.; LLOYD, B. B. (Eds.). Cognition and categorization. Hillsdale, N.J.; New York: L. Erlbaum Associates, distributed by Halsted Press, 1978.

ROYCE, T. D.; BOWCHER, W. L. (Eds.). New directions in the analysis of multimodal discourse. Mahwah, N.J.: L. Erlbaum Associates, 2007.

SCHIFFRIN, D.; TANNEN, D.; HAMILTON, H. E. (Eds.). The Handbook of Discourse Analysis 2. ed. Malden, Mass.: Blackwell, 2013.

SEARLE, J. Speech Acts: An Essay in the Philosophy of Language. Cambridge: Cambridge University Press, 1969.

SHIPLEY, T. F.; ZACKS, J. M. (Eds.). Understanding events. From perception to action. Oxford; New York: Oxford University Press, 2008. http://dx.doi.org/10.1093/acprof:o so/9780195188370.001.0001

SPERBER, D.; WILSON, D. Relevance: Communication and cognition. Cambridge, MA Blackwell, 1995.

STEWART, A. Theories of power and domination. The politics of empowerment in late modernity. London Thousand Oaks, Calif.: SAGE, 2001.

TITSCHER, S.; MEYER, M.; WODAK, R.; VETTER, E. Methods of text and discourse analysis. London: Thousand Oaks; Calif.: SAGE, 2000. 
TOMASELlO, M. (2008). Origins of Human Communication. Cambridge, MA: MIT Press, 2008.

TULVING, E. Elements of episodic memory. Oxford Oxfordshire New York: Clarendon Press, Oxford University Press, 1983.

Episodic memory: From mind to brain. Annual Review of Psychology, 53 (1), 1-25, 2002. http://dx.doi.org/10.1146/annurev.psych.53.100901.135114

TULVING, E.; CRAIK, F. I. M. (Eds.). The Oxford handbook of memory. Oxford; New York: Oxford University Press, 2000.

VAN DIJK, T. A. Prejudice in discourse. An analysis of ethnic prejudice in cognition and conversation. Amsterdam Philadelphia: J. Benjamins, 1984. http://dx.doi.org/10.1075/ pb.v.3

Communicating racism: Ethnic prejudice in thought and talk. Newbury Park, CA: Sage Publications, 1987.

Racism and the press. London; New York: Routledge, 1991.

Elite discourse and racism. Newbury Park, Calif.: Sage Publications, 1993.

Ideology: A multidisciplinary approach. London, England: Sage Publications, 1998.

Multidisciplinary CDA: A Plea for Diversity. In: WODAK, Ruth; MEYER, Michael (Eds.). Methods of Critical Discourse Analysis. London: Sage. p. 95-120, 2001. http:// dx.doi.org/10.4135/9780857028020.d7

Discourse and context. A socio-cognitive approach. Cambridge; New York: Cambridge University Press, 2008a.

Discourse and power. Houndmills, Basingstoke, Hampshire New York: Palgrave Macmillan, 2008b.

Society and discourse. How social contexts influence text and talk. Cambridge; New York: Cambridge University Press, 2009a.

Discourse and Knowledge. Cambridge: Cambridge University Press (in preparation), 2014. http://dx.doi.org/10.1017/CB09781107775404

(Ed.). Discourse Studies. 5 vols. Sage Benchmarks in Discourse Studies. London: Sage, 2007

(Ed.). Racism and Discourse in Latin America. Lanham: Lexington Books, 2009b.
VAN DIJK, T. A.; KINTSCH, W. Strategies of discourse comprehension. New York; Toronto: Academic Press, 1983

ZWAAN, R. A. The immersed experiencer: Toward an embodied theory of language comprehension. Psychology of Learning and Motivation: Advances in Research and Theory, $44,35-62,2004$

Recebido em 25/02/2016 Aceito em 25/02/2016. 